\begin{tabular}{|c|l|}
\hline Title & Pollination Efficiency of Bumblebee Queens and Workers in the A Ipine Shrub Rhododendron aureum \\
\hline Author(s) & Kudo, Gaku; Hirao, A kira S.; Kawai, Yuka \\
\hline Citation & $\begin{array}{l}\text { International Journal of Plant Sciences, 172(1), 70-77 } \\
\text { https://doi.org/10.1086/657282 }\end{array}$ \\
\hline Issue Date & 2011-01 \\
\hline Doc URL & http://hdl.handle.net/2115/47946 \\
\hline Rights & Distributed under licence by JSTOR. \\
\hline Type & article \\
\hline File Information & IJPS172-1_70-77.pdf \\
\hline
\end{tabular}

Instructions for use 
Pollination Efficiency of Bumblebee Queens and Workers in the Alpine Shrub Rhododendron aureum

Author(s): Gaku Kudo, Akira S. Hirao, Yuka Kawai

Source: International Journal of Plant Sciences, Vol. 172, No. 1 (January 2011), pp. 70-77

Published by: The University of Chicago Press

Stable URL: http://www.jstor.org/stable/10.1086/657282

Accessed: 23/02/2011 10:16

Your use of the JSTOR archive indicates your acceptance of JSTOR's Terms and Conditions of Use, available at http://www.jstor.org/page/info/about/policies/terms.jsp. JSTOR's Terms and Conditions of Use provides, in part, that unless you have obtained prior permission, you may not download an entire issue of a journal or multiple copies of articles, and you may use content in the JSTOR archive only for your personal, non-commercial use.

Please contact the publisher regarding any further use of this work. Publisher contact information may be obtained at http://www.jstor.org/action/showPublisher?publisherCode=ucpress.

Each copy of any part of a JSTOR transmission must contain the same copyright notice that appears on the screen or printed page of such transmission.

JSTOR is a not-for-profit service that helps scholars, researchers, and students discover, use, and build upon a wide range of content in a trusted digital archive. We use information technology and tools to increase productivity and facilitate new forms of scholarship. For more information about JSTOR, please contact support@jstor.org. 
Int. J. Plant Sci. 172(1):70-77. 2011.

(c) 2011 by The University of Chicago. All rights reserved.

1058-5893/2011/17201-0005\$15.00 DOI: $10.1086 / 657282$

\title{
POLLINATION EFFICIENCY OF BUMBLEBEE QUEENS AND WORKERS IN THE ALPINE SHRUB RHODODENDRON AUREUM
}

\author{
Gaku Kudo, ${ }^{1, *}$ Akira S. Hirao, $†$ and Yuka Kawai* \\ *Faculty of Environmental Earth Science, Hokkaido University, Sapporo 060-0810, Japan; and tInstitute of \\ Mountain Science, Shinshu University, Matsumoto 390-8621, Japan
}

\begin{abstract}
Rhododendron aureum is a weakly self-compatible alpine shrub pollinated by bumblebees. Flower visitation frequency and foraging behavior differed between queen bumblebees and workers. Queens exhibited less frequent flower visits, longer flight distances between inflorescences, and a smaller number of sequential inflorescence visits within patches than did worker bees. Flowering in early-snowmelt populations occurred in June, when only overwintered queens were available, while flowering in late-snowmelt populations occurred from late July to August, when frequent visits by workers were common. The fruit to flower ratio per inflorescence was lower in early-snowmelt populations due to quantitative pollen limitation, while the seed to ovule ratio per fruit was lower in late-snowmelt populations. This is because geitonogamous pollination by workers was common later in the season, which resulted in a high abortion rate of self-pollinated seeds, that is, qualitative pollen limitation. Thus, pollination efficiency, or the type of pollen limitation, shifts during the flowering season, reflecting the seasonal life cycle of bumblebees in the ecosystem. Many of the self-fertilized seeds aborted due to high inbreeding depression, and the outcrossing rate was $\sim 80 \%$ regardless of season.
\end{abstract}

Keywords: alpine plants, bumblebee, flowering phenology, geitonogamous pollination, pollen limitation, mating system.

\section{Introduction}

Pollinator activity and behavior can be major factors affecting pollen limitation (Burd 1994; Olsen 1997; Fenster et al. 2004). Low pollinator visitation often limits seed production simply because of the small amount of pollen received, that is, quantitative pollen limitation. In contrast, even under conditions with frequent visitations, the longer pollinators stay at a flower, an inflorescence, or a plant, the greater the potential for autogamous pollination, geitonogamous pollination, or biparental inbreeding, all of which can result in qualitative pollen limitation (de Jong et al. 1993). Furthermore, deposition of self-pollen on stigmas may interfere with outcrossing even when enough outcross pollen is received if stigma clogging (Lloyd and Yates 1982) or ovule discounting (Waser and Price 1991; Eckert 2000; Nuortila et al. 2002) occur. Therefore, the effectiveness of the pollinator situation depends strongly on postpollination properties of the plant species.

Variation in pollinator effectiveness among populations has been commonly studied at spatial scales containing different pollinator groups in which pollination success of individual populations can be influenced by local pollinator fauna (e.g., Brunet and Sweet 2006; Moeller 2006). In addition, pollinator activity often varies seasonally, reflecting climatic conditions (Inouye and Pyke 1988; Bergman et al. 1996) or events in the life cycle of pollinator species, such as the migration schedule of nectar-feeding birds (Ramsey $1995 a$ ) and colony growth in social bees (Tomono and Sota

${ }^{1}$ Author for correspondence; e-mail: gaku@ees.hokudai.ac.jp.

Manuscript received June 2010; revised manuscript received August 2010.
1997). Temporal variation in pollinator effectiveness may influence the pollination success of plant species that have prolonged flowering seasons (Kudo 1993; Ramsey 1995a).

The alpine ecosystem is an ideal location in which to study the seasonal variation in pollinator effectiveness and its impact on pollination success. Flowering in alpine plants is strongly determined by time of snowmelt, and the flowering period of a single species lasts throughout summer over populations situated along the snowmelt gradient (Kudo 1991). In the alpine ecosystems of the Northern hemisphere, bumblebees (Bombus spp.) are highly effective pollinators, and their activity varies considerably as the alpine plant growing season progresses, resulting in a clear seasonal trend in visitation frequency to flowers (Kameyama and Kudo 2009). Fruit-set success in beepollinated alpine plants varies, reflecting the seasonality of bumblebee activity (Kudo and Suzuki 2002).

In a previous study, we demonstrated that a late-flowering population of Rhododendron aureum Georgi (Ericaceae) located in a snowbed habitat was predominantly visited at a higher frequency by worker bees, but seed production within fruits was smaller in comparison with that in an early-flowering fellfield population, where only queen bees visited at a lower frequency (Hirao et al. 2006). This trend was presumably caused by frequent geitonogamous pollination and/or biparental inbreeding mediated by worker bees, resulting in higher rates of abortion of selfed seeds due to inbreeding depression. Hand-pollination experiments revealed that self-pollinated flowers produced a significantly smaller number of seeds than did outcrossed flowers, although both selfed and outcrossed flowers showed high fruit-set success. However, the interference effect of self-pollen deposition on seed production was not tested in our previous study. If fertilization with 
outcross pollen has priority over self-fertilization in a situation with mixed pollination, the effect of self-pollen deposition on seed production may be small (Kameyama and Kudo 2009). Furthermore, we did not previously document the relationship between the foraging behavior of bumblebees and geitonogamous pollination.

We now attempt to answer the following three questions. First, how does flowering time influence pollinator visitation and fruit production in $R$. aureum (i.e., the seasonal trend of quantitative pollen limitation)? In our previous study (Kudo 1993), later-flowering populations inhabiting a snowbed habitat in 1990 and 1991 displayed both larger numbers of pollinator visits and higher fruit-set ratio than did an early-flowering population inhabiting an exposed fellfield habitat with little snow cover. However, the difference in fruit-set success was not clear between the fellfield and snowbed populations in 2003 in the same area (Hirao et al. 2006). Because the timing of snowmelt varies from year to year, a longer observation period of fruiting pattern and pollinator visits is necessary to understand general trends. Second, how do queen bumblebees, nectarforaging workers, and pollen-foraging workers differ in their patterns of floral visitation and pollen deposition on stigmas? In June, overwintered queens occasionally visit $R$. aureum flowers for nectar before nesting, whereas worker bees intensively collect nectar or nectar and pollen from late July to late August. Finally, how does the foraging behavior of bumblebees influence seed production with reference to the mating properties of this species? Not only pollinator caste but also whether a bee is collecting nectar or pollen may influence pollination efficiency (Freitas and Paxton 1998; Young et al. 2007; Ono et al. 2008).

\section{Material and Methods}

\section{Study Site}

This study was conducted in the central part of the Taisetsu Mountains in Hokkaido, northern Japan. The climate of the Taisetsu Mountains is characterized by warm, wet summers and cold, snowy winters. Annual mean temperature at 1700 $\mathrm{m}$ elevation is $-2.0^{\circ} \mathrm{C}$, ranging from $-16.3^{\circ} \mathrm{C}$ in January to $13.0^{\circ} \mathrm{C}$ in August. Plant growth starts in late May in earlysnowmelt locations, and the growth season lasts until midSeptember. We selected two fellfield plots, hereafter F1 (1710 $\mathrm{m}$ elevation) and F2 (1910 m elevation), and two snowbed plots, hereafter S1 (1860 m elevation) and S2 (1810 m elevation), around Lake Hisago $\left(43^{\circ} 33^{\prime} \mathrm{N}, 142^{\circ} 52^{\prime} \mathrm{E}\right)$ in which Rhododendron aureum was a dominant plant species. Each plot was $\sim 20 \times 20 \mathrm{~m}$ in size. F1 was located on a plateau 100 $\mathrm{m}$ above the timberline, and F2 was located on a ridge. Both fellfield plots were usually free of snow cover by mid-April and were dominated by lichens and dwarf shrubs. In contrast, the snowbed plots were usually exposed around mid- to late July, and herbaceous species were common there. F2 and D2 corresponded to the early and late snowmelt plots, respectively, in our previous study (Hirao et al. 2006).

\section{Plant Material}

Rhododendron aureum is an evergreen dwarf shrub distributed in the alpine regions of northeastern Asia. This species has a wide distribution range, from fellfield to snowbed sites, in the Taisetsu Mountains, and its flowering season lasts from early June in early-snowmelt fellfield sites to mid-August in late-snowmelt snowbed sites (Kudo 1991, 1993). Each inflorescence contains two to five cream-yellow flowers that open synchronously and have a longevity of 7-10 d. Self-pollinated flowers can produce fruit, but autogamous selfing is rare (Kudo 1993). Thus, the fruit-set ratio essentially reflects the activity of pollinators in this species. The major pollinators for $R$. aureum are bumblebees, small solitary bees, and various flies (Kudo 1993), but the most effective pollinators seem to be bumblebees (Hirao et al. 2006). Flowers in the fellfield populations are commonly visited by overwintered queens, while flowers in the snowbed populations are predominantly visited by worker bees. Self-pollinated flowers produce smaller numbers of seeds than do outcrossed flowers, indicating the existence of partial self-sterility (Hirao et al. 2006). Fruits mature 50-60 d after flowering (Kudo 1993).

\section{Flowering Phenology and Reproductive Success}

The beginning and end of flowering was observed in each plot every year from 2003 to 2007. Flowering period (from first flowering to the completion of flowering in each plot) was observed at 5-7-d intervals on average. Fruit-set success (i.e., fruit to flower ratio) under natural pollination was measured in 2006 and 2007 to evaluate pollinator activity. For the measurement of fruit-set success, 35-100 inflorescences were randomly selected and tagged for identification before flowering in each plot, the number of flowers was recorded over the flowering period, and the number of mature fruits was counted during the fruiting period to calculate the fruit-set ratio. In the fruiting period, 30-35 infructescences with mature fruits were selected randomly from each plot, and one fruit was harvested before seed dispersal. In the laboratory, the numbers of seeds and undeveloped seeds or ovules were counted using a microscope, and the seed-set ratio (i.e., seed to ovule ratio) was calculated. Seed-set success was measured in only F2 and S2 because there were seed-set records for those plots in our previous study ( $\mathrm{Hi}$ rao et al. 2006). In the analyses of fruit set and seed set, we added data for 2003 (from Hirao et al. 2006) in which F2 and D2 data were available.

\section{Outcrossing Rate}

The outcrossing rate of naturally pollinated flowers in 2006 was estimated for 24 and 26 fruits in F2 and D2, respectively. Each fruit was sampled from different inflorescences, and two to four seeds per fruit were used for analysis. Five microsatellite markers (RM2D2, RM3D1, RM9D1, RM9D6 [Naito et al. 1998], and RM9D9 [Hirao et al. 2006]) were used to determine whether seeds were outcrossed or selfed. Extraction of genomic DNA was performed in accordance with Hirao et al. (2006). Polymerase chain reaction (PCR) amplification was performed with a GeneAmp PCR System 9700 (Applied Biosystems, Foster City, CA). The size of PCR products was determined using an ABI PRISM 3100 automated sequencer and GENESCAN analysis software. The maternal alleles of individual inflorescences were obtained from leaves, and the direct estimator of the outcrossing rate, 
which was determined by the presence of nonmaternal alleles, was used for a comparison between fellfield (F2) and snowbed (S2) populations. To confirm the outcrossing rate, paternity exclusion probability was calculated from the allele frequencies of the loci (Weir 1996).

\section{Pollination Experiment}

To evaluate the interference of self-pollen deposition with seed production, we conducted a hand-pollination experiment in 2008. We selected 20 inflorescences with more than three floral buds in S1 and covered them with fine-meshed nylon bags. When all of the flowers opened, we selected three flowers and the others were removed. Then, the following three pollination treatments were performed on one of three flowers on an inflorescence: (1) self-pollination, (2) outcross pollination with pollen from a donor plant located $>10 \mathrm{~m}$ from a recipient plant, and (3) mixed pollination with selfand outcross pollen. In the mixed pollination treatment, selfpollen was deposited on stigmas first, and then outcross pollen was deposited immediately thereafter. This pattern simulated the condition of frequent geitonogamous pollination, in which receipt of self-pollen is common in comparison with the deposition of outcross pollen on stigmas. Hand pollination was performed until the stigma surface was completely covered with pollen. After hand pollination, inflorescences were again covered with nylon bags until the end of the flowering period. When the fruits matured, they were harvested, and seed-set success was measured as described above. Inbreeding depression $(\delta)$ was calculated as $\delta=\left(r_{\text {out }}-r_{\text {self }}\right) / r_{\text {out }}$, where $r_{\text {out }}$ is the seed-set ratio by outcross pollination and $r_{\text {self }}$ is the seed-set ratio by self-pollination within inflorescences. Similarly, the interference effect of self-pollen in the mixed-pollination $(I)$ was calculated as $I=\left(r_{\text {out }}-r_{\text {mix }}\right) / r_{\text {out }}$, where $r_{\text {mix }}$ is the seed-set ratio by mixed pollination.

\section{Pollinator Observation}

Visitation frequency and foraging behavior of bumblebees were observed in the fellfield and snowbed populations and in nearby plots in 2007. Observation of visitation frequency was conducted for $1 \mathrm{~d}$ (over $6 \mathrm{~h}$ ), and that of foraging behavior was observed for $3 \mathrm{~d}\left(1-3 \mathrm{~h} \mathrm{~d}^{-1}\right)$ at peak flowering season under sunny and calm conditions in each fellfield and snowbed plot. In each observation day, a $10 \times 10$-m quadrat was set at the central part of the population, and the number of inflorescences within that quadrat was counted. Then, the number of bumblebees that visited the quadrat, the number of sequential inflorescence visits within the quadrat, the flight distance between inflorescences, and foraging behavior (nectar or pollen foraging) were recorded in addition to the identification of species and caste (queen or worker) of individual bumblebees. Flight distance was recorded by eye along a 10$\mathrm{cm}$ interval scale as accurately as possible.

For the comparison of the effectiveness of pollination between queen and worker bees, pollen deposition on stigmas during a first visit and during a 24 -h period was measured in the fellfield and snowbed populations in 2007. In the measurement, during a first visit, newly opened flowers without pollen deposition on their stigmas were tagged and then ob- served until a bumblebee visited the flower. After the first visit, the stigma was cut off and put on a cell plate filled with agar medium. In the laboratory, using a microscope, the number of pollen grains on the stigma was counted. In the 24-h exposure measurement, newly opened flowers were tagged on the morning of a fine and calm day and exposed for natural pollination. After $24 \mathrm{~h}$, the number of pollen grains on each stigma was counted as described above. In the fellfield populations, the stigmas of 15 and 58 flowers were checked during a first visit and during 24-h exposure measurements, respectively. In the snowbed populations, the number of samples was 19 and 20 flowers, respectively.

\section{Statistical Analyses}

Fruit set and seed set under natural conditions were compared between fellfield and snowbed habitats by a generalized linear mixed model (GLMM) comprising a logit link function and a binomial error distribution in which the number of flowers that did and did not set fruits within inflorescences (for fruit set) or the number of ovules that did or did not turn into seeds within fruits (for seed set) were the data sources. In the GLMM, year (2003, 2006, 2007) and plot (F1, F2, S1, S2; only for fruit-set analysis) were treated as random factors. Furthermore, inflorescence (for fruit set) or fruit (for seed set) was also considered as a random factor. The outcrossing rate in 2006 was compared between a fellfield plot (F2) and a snowbed plot (S2) by GLMM, comprising a logit link function and a binomial error distribution in which plot was a fixed factor and fruit was a random factor. Seed set of the pollination experiment was compared among treatments (self-, mixed, and outcross pollination) by GLMM, comprising a logit link function and a binomial error distribution in which treatment was treated as a fixed factor. The random factors were hierarchically defined as dependent on fruits nested within inflorescences. Pollen deposition on stigmas in 2007 was compared between fellfield and snowbed plots by a generalized linear model (GLM), comprising a Poisson error distribution. Foraging behavior of bumblebees (number of flower visits per

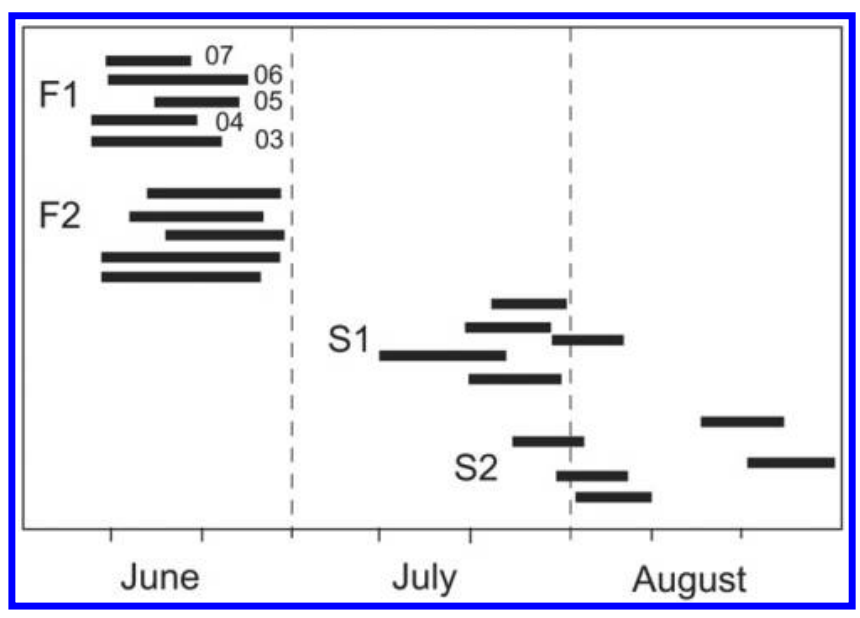

Fig. 1 Yearly variation in the flowering period of Rhododendron aureum in each plot during the period 2003-2007. F1 and F2 are fellfield populations and $S 1$ and $S 2$ are snowbed populations. 
inflorescence, interinflorescence flight distance, and number of sequential inflorescence visits within a quadrat) was compared among queens, nectar-collecting workers, and pollen-collecting workers by a linear mixed effect model (LME) comprising a Gaussian error distribution in which the observation quadrat was treated as a random factor. In the analysis of foraging behavior, mean values of individual bees were used for LME. All statistical analyses were performed using R, version 2.10.0 (http://www.R-project.org).

\section{Results}

\section{Flowering Phenology}

The flowering periods of individual plots from 2003 to 2007 are shown in figure 1. Flowering in F1 and F2 frequently started in the middle of June and lasted until the end of June. Flowering in the snowbed plots varied substantially from year to year, depending on snowmelt time. Flowering in S1 occurred from mid-July to early August, while the flowering season in S2 was from late July to late August. The mean flowering periods of individual plots were 13 days in F1, 16 days in F2, 11 days in S1, and 9 days in S2.

\section{Fruit Set and Seed Set}

The fruit-set ratio of every plot and the seed-set ratio of F2 and S2 are shown in figure 2. Fruit set under natural pollination was significantly lower in the fellfield (F1 and F2) than in the snowbed (S1 and S2; $P=0.0039$ by GLMM). The mean fruit-set ratio was $0.43-0.65$ in the fellfield populations, while it was $0.57-0.89$ in the snowbed populations. In contrast, the seed-set ratio per fruit showed the opposite

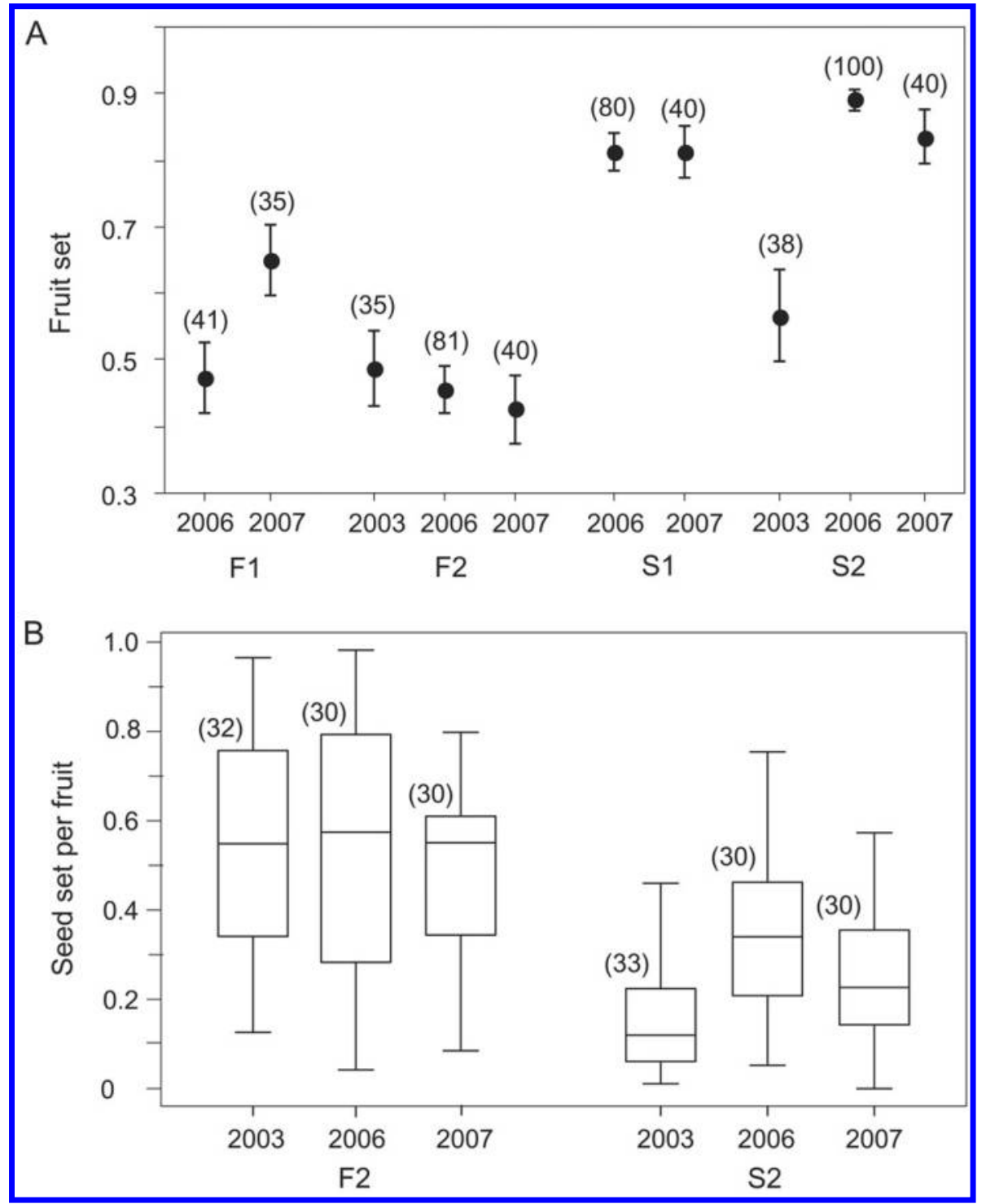

Fig. 2 Fruit-set ratio per inflorescence $(A)$ and seed-set ratio per fruit $(B)$ under natural pollination. Mean \pm SE for fruit set. Sample sizes are shown in parentheses. Box-and-whisker plots represent the seventy-fifth, fiftieth, and twenty-fifth percentiles (boxes), with whiskers indicating the ninetieth and tenth percentiles. Data from 2003 were reported by Hirao et al. (2006). 


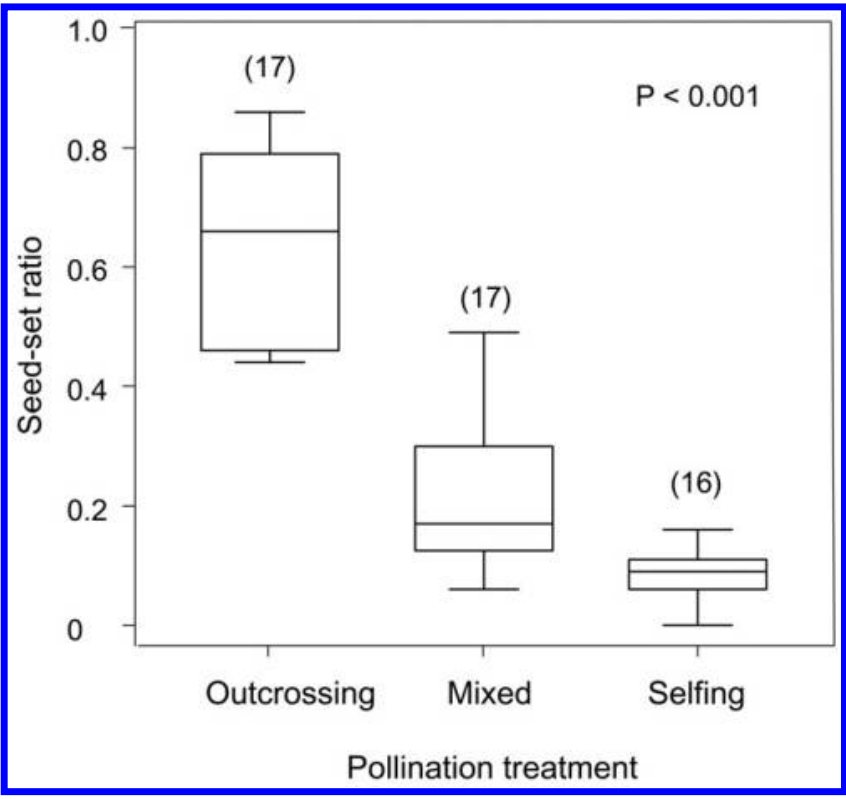

Fig. 3 Seed-set ratio in the hand-pollination experiment: outcross, mixed, and self-pollination. The sample size of each treatment is shown in parentheses. Treatment effect on seed-set ratio was significant $(P<$ 0.001 ) by a generalized linear mixed model.

pattern between fellfield and snowbed: it was higher in F2 $(0.49-0.54)$ than in S2 (0.15-0.35), and this difference was significant $(P=0.012$ by GLMM).

With all of the microsatellite loci combined, paternity exclusion probability was high enough $(>0.99)$ to directly assign selfed or outcrossed seed. The outcrossing rate in 2006 was $0.79 \pm 0.05 \mathrm{SE}(n=24)$ in F2 and $0.77 \pm 0.06(n=$ $26)$ in S2. In 2003, outcrossing rate was $0.85 \pm 0.07(n=$ 12 ) in F2 and $0.69 \pm 0.07(n=12)$ in S2 (Hirao et al. 2006). GLMM revealed that there were no significant differences in outcrossing rates between F2 and S2 $(P=0.23)$ or between 2003 and $2006(P=0.59)$.

\section{Mating System}

Most of the hand-pollinated flowers that were not lost accidentally set fruits irrespective of pollination treatment (i.e., self-, outcross, and mixed pollen). The seed-set ratio was significantly different between pollination treatments $(P<$ $0.001)$. Seed-set ratio of outcrossed flowers was $0.64 \pm 0.04$
SE, while that of self-pollinated flowers averaged only $0.08 \pm$ 0.01 (fig. 3), indicating high inbreeding depression $(\delta)$ for seed set. The measure of inbreeding depression was $0.86 \pm$ $0.02(n=13)$. The seed-set ratio of mixed pollination showed intermediate values, indicating the existence of interference by self-pollination. The interference effect $(I)$ was $0.69 \pm 0.04(n=13)$.

\section{Visitation Frequency and Behavior of Bumblebees}

In the fellfield plots, only overwintered queens of Bombus bypocrita sapporoensis were observed on R. aureum flowers, and visitation frequency was low, $<0.1$ visits per inflorescence per hour (table 1). In contrast, visitation frequency in the snowbed plots was $>10$ times higher than that in the fellfield plots, and snowbed flowers were predominantly visited by workers of $B$. hypocrita sapporoensis.

During $17 \mathrm{~h}$ of observation throughout the plots, the foraging behavior of $150 \mathrm{~B}$. hypocrita sapporoensis was recorded. Bumblebees visited $1.8 \pm 0.05$ (mean \pm SE) flowers within inflorescences, and there was no difference between queens and workers $(P>0.10$; fig. $4 A)$. The flight distance between inflorescences was significantly longer for queens $(123 \pm 38 \mathrm{~cm})$ in comparison with workers $(44 \pm 2 \mathrm{~cm} ; P<$ 0.05 ; fig. $4 B$ ). The sequential number of inflorescence visits within a $10 \times 10$-m quadrat was significantly different among queens (11 \pm 3 inflorescences), workers foraging for nectar (25 \pm 3 inflorescences), and workers foraging for pollen (36 \pm 3 inflorescences; $P<0.001$; fig. $4 C$ ). These results suggest that geitonogamous pollination was more common for workers than for queens, and especially for workers collecting pollen.

\section{Pollen Deposition on the Stigma}

The number of pollen grains deposited on the stigma during a first visit by a bumblebee was not significantly different between a fellfield plot (F2) visited by queens and a snowbed plot (S2) visited by workers $(P>0.10$; fig. $5 A)$. The number of pollen grains deposited on the stigma during a 24-h period was significantly greater in S2 than in F2 $(P<0.001$; fig. $5 B$ ), reflecting the visitation frequency in each plot (table 1). Interestingly, the twenty-fifth to seventy-fifth percentile boxes of F2 were similar between first visit exposure and after $24 \mathrm{~h}$ of exposure, while the median number of pollen grains was quite contrastive: that of $24 \mathrm{~h}$ of exposure was almost 0 (fig. 5 ). This indicates that pollinator visitation was limited and occasional in F2.

Table 1

Visitation Frequency of Bumblebees to Inflorescences per Hour and the Number of Bumblebee Species Observed in Each Plot

\begin{tabular}{lcccccc}
\hline & & \multicolumn{2}{c}{ Bombus hypocrita sapporoensis } & & \multicolumn{2}{c}{ Bombus beaticola moshkarareppus } \\
\cline { 3 - 4 } Plot & Visits per hour & Queen & Worker & & Queen & Worker \\
\hline F1 & 0.098 & 7 & 0 & & 0 & 0 \\
F2 & 0.067 & 10 & 0 & & 0 & 0 \\
S1 & 2.62 & 3 & 142 & & 0 & 4 \\
S2 & 1.25 & 2 & 96 & & 2 & 5 \\
\hline
\end{tabular}

Note. Observation was conducted in 2007 within a $10 \times 10$-m quadrat on June 14 in F1, June 20 in F2, July 27 in S1, and August 8 in S2. The observation period was 6 h. 


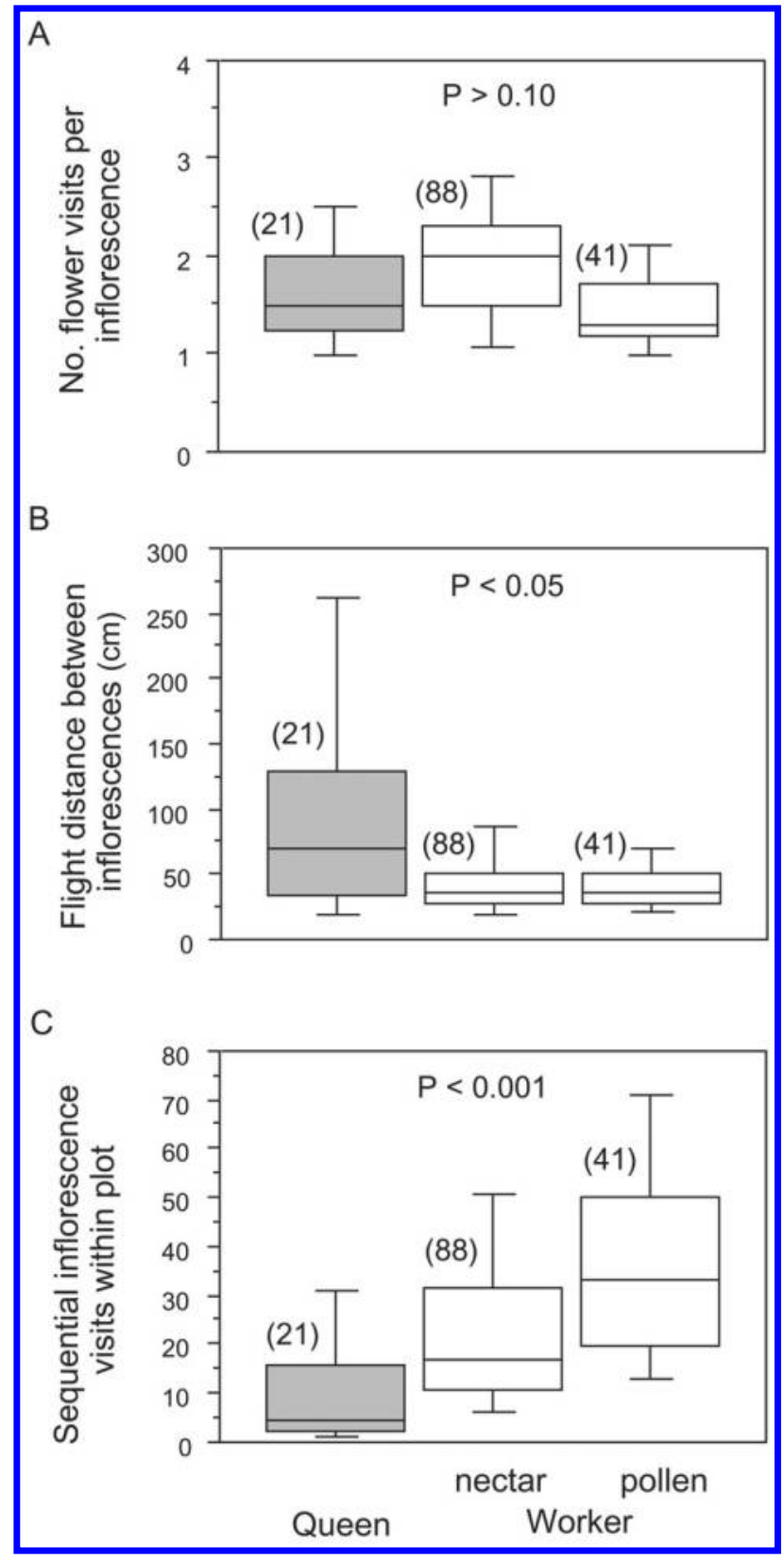

Fig. 4 Foraging behavior of bumblebees on Rhododendron aureum patches. $A$, The number of flower visits within an inflorescence; $B$, flight distance between inflorescences; $C$, the number of sequential inflorescence visits within a $10 \times 10$-m quadrat. The sample size is shown in parentheses. Observation of queen bees was conducted in fellfield populations, and that of worker bees was done in snowbed populations. Significance level by generalized linear mixed model is shown.

\section{Discussion}

\section{Pollinator Situation}

Fruit production of Rhododendron aureum was greater in the snowbed populations than in the fellfield populations, as reported in our previous studies (Kudo 1993; Kudo and
Suzuki 2002). Because self- and outcross-pollinated flowers showed similarly high fruit sets, the variation in the fruit-set ratio among populations reflected quantitative pollen limitation. Because both queens and workers deposited similar numbers of pollen grains on each stigma during a single visit, the low visitation frequency of queens resulted in low fruit set in the fellfield populations.

In a number of plant species in the alpine area of northern Japan, fruit production of bee-pollinated plants is usually low in the early season (June to early July) and increases as the season progress (Kudo and Suzuki 2002). Overwintered bumblebee queens are the major pollinators from June to mid-July, but their visitation frequency is usually low because of the small population of queens and the cool climate. Worker bees normally appear in late July in the alpine regions of Hokkaido, and visitation frequency increases drastically (>100 times in comparison with visitation by queens) as colonies grow during the warmer season. The high-activity period of the worker bees lasts until late August (Kameyama and Kudo 2009). Such a very clear seasonality of pollinator activity is characteristic of alpine ecosystems.

This study revealed that the high activity of worker bees resulted in decreased pollination efficiency due to a higher level of geitonogamous pollination. This was because worker bees exhibited shorter flight distances between inflorescences and longer periods of staying within a given patch. Although the differences in foraging behavior between bumblebee castes have been reported previously (e.g., Macior 1966; Ranta and Lundberg 1981; Ono et al. 2008), current information on the pollination effectiveness of queens and workers is very limited. In this study, geitonogamous pollination increased with visitations by workers. These results indicate the existence of a trade-off between quantitative pollen limitation and qualitative pollen limitation within the flowering season.

\section{Mating Properties}

The effects of pollinator activity and behavior on seed production strongly depend on the mating system of the plant species. For instance, seed-set ratio in Phyllodoce aleutica, a bumblebee-pollinated shrub inhabiting alpine snowbed habitats, varied from 0.18 to 0.83 among neighboring populations located in different snowmelt conditions (Kameyama and Kudo 2009). This reflects the significance of seasonality in bumblebee activity for the reproduction of alpine plants. Furthermore, the outcrossing rate of $P$. aleutica increased from 0.10 to 0.88 with an increase in seed-set ratio. This was because $P$. aleutica showed selective outcrossing when both selfand outcross pollen were deposited on stigmas without prior interference by self-pollen, that is, cryptic self-incompatibility (Kameyama and Kudo 2009).

In contrast, in R. aureum, interference by self-pollen deposition was deleterious. Seed production of mixed-pollinated flowers decreased by $69 \%$ in comparison with outcrossed flowers, while seed production of self-pollinated flowers decreased by $86 \%$. The strong depression effect of mixed pollination might be because self-pollen was deposited before outcross pollen during the hand pollinations. However, this situation may be common under natural pollination because 


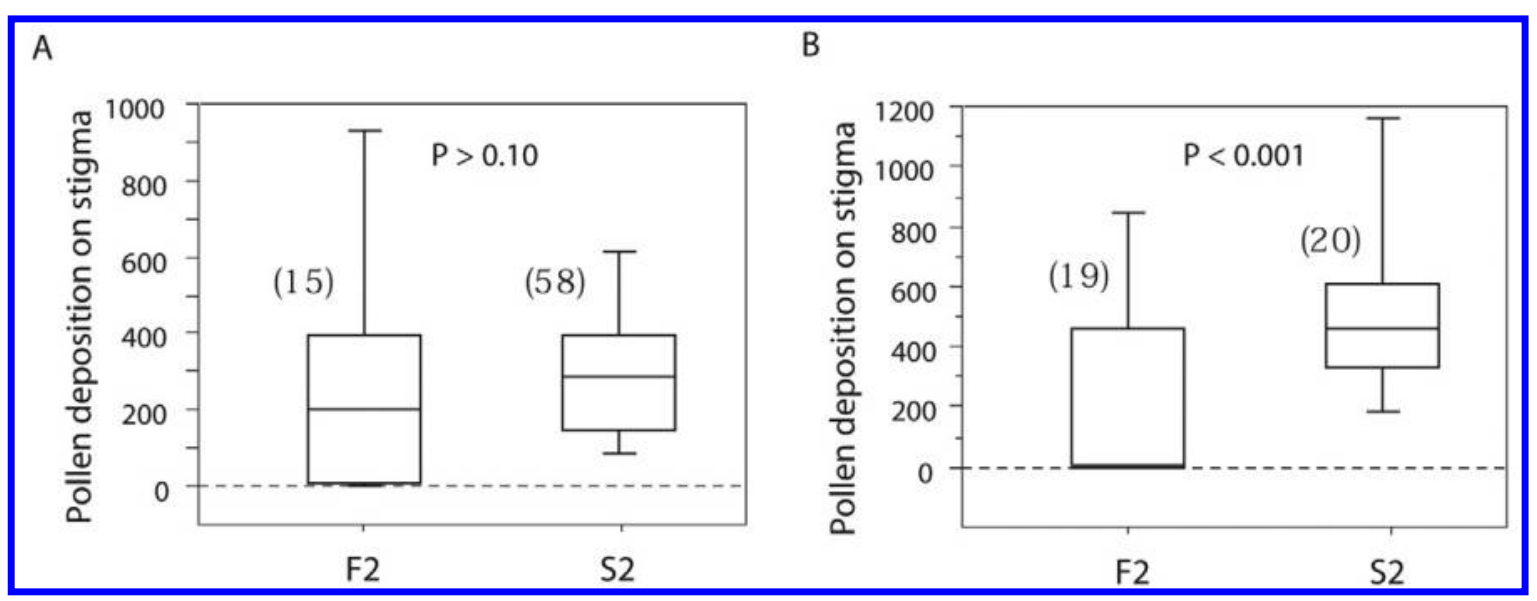

Fig. 5 The number of pollen grains deposited on the stigmas during a first visit of bumblebees $(A)$ and during $24 \mathrm{~h}$ of exposure $(B)$ in the fellfield (F2) and snowbed (S2) plots. The sample size of each treatment is shown in parentheses. Significance level by generalized linear mixed model is shown.

$R$. aureum often produces clonal patches, with diameters of a few meters up to $12 \mathrm{~m}$, with limited intermingling of genets, in which geitonogamous pollination can occur easily (Eckert 2000). A decrease in seed set because of self-pollination might be caused by partial abortion of self-fertilized seeds at an early stage because aborted seeds were clearly larger than ovules (G. Kudo, personal observation).

Partial self-sterility due to inbreeding depression has been reported in other Rhododendron species (Hirao 2010) and in several ericaceous species, such as Vaccinium myrtillus, Vaccinium angustifolium, Vaccinium corymbosum, and Vaccinium vitis-idaea (Guillaume and Jacquemart 1999; Hokanson and Hancock 2000; Nuortila et al. 2002, 2006; Raspé et al. 2004). When ovules are preempted by self-pollen before cross-fertilization, total seed production should be substantially reduced (Ramsey 1995b). Therefore, the impact of geitonogamous pollination in these species should be significant.

In a previous study, Kudo (1993) speculated that seed production by selfing might be common in fellfield populations of $R$. aureum because of lower pollinator visitation rates and lower fruit production. However, this study showed that fellfield and snowbed populations had similarly high outcrossing rates $(\sim 80 \%)$ in mature seeds due to the high abortion rate of selfed seeds caused by strong inbreeding depression. However, the high fruit-set ratio we observed following self-pollination indicates that, despite the inbreeding depression that accom- panies selfing, enough ovules mature as seeds to simulate fruit development. A similar situation has been reported in another ericaceous shrub, V. myrtillus (Raspé et al. 2004).

\section{Conclusions}

The pollination situation in alpine ecosystems clearly changes quantitatively and qualitatively through the flowering season, reflecting the life cycle of bumblebees. Acceleration of pollinator activity accompanied by increasing risk of geitonogamous pollination brings about an opposing pattern of fruit production and seed production per fruit in $R$. aureum. However, the effects of such a pollination situation on reproductive output vary depending on the mating system of the individual plant species. This indicates the importance of genetic milieu in understanding the sensitivity of plant reproduction to pollinator availability under conditions with clear seasonality.

\section{Acknowledgments}

We thank Y. Kameyama for field support. This study was supported by grants-in-aid from the Ministry of Environment of Japan, the Global Environmental Research Fund (F052 and F-092), and the Japan Society for the Promotion of Science (21370005).

\section{Literature Cited}

Bergman P, U Molau, B Holmgren 1996 Micrometeorological impacts on insect activity and plant reproductive success in an alpine environment, Swedish Lapland. Arct Alp Res 28:196-202.

Brunet J, HR Sweet 2006 Impact of insect pollinator group and floral size on outcrossing rate. Evolution 60:234-246.

Burd M 1994 Bateman's principle and plant reproduction: the role of pollen limitation in fruit and seed set. Bot Rev 60:83-139.

de Jong TJ, NM Waser, PGL Klinkhamer 1993 Geitonogamy: the neglected side of selfing. Trends Ecol Evol 8:321-325.
Eckert CG 2000 Contributions of autogamy and geitonogamy to selffertilization in a mass-flowering, clonal plant. Ecology 81:532-542.

Fenster CB, WS Armbruster, P Wilson, MR Dudash, JD Thomson 2004 Pollination syndromes and floral specialization. Annu Rev Ecol Syst 35:375-403.

Freitas BM, RJ Paxton 1998 A comparison of two pollinators: the introduced honey bee Apis mellifera and an indigenous bee Centris tarsata on cashew Anacardium occidentale in its native range of $\mathrm{NE}$ Brazil. J Appl Ecol 35:109-121. 
Guillaume P, A-L Jacquemart 1999 Early-inbreeding depression in Vaccinium myrtillus and V. vitis-idaea. Protoplasma 208:107-114.

Hirao AS 2010 Kinship between parents reduces offspring fitness in a natural population of Rhododendron brachycarpum. Ann Bot 105:637-646.

Hirao AS, Y Kameyama, M Ohara, Y Isagi, G Kudo 2006 Seasonal changes in pollinator activity influence the pollen dispersal and seed production of the alpine shrub Rhododendron aureum (Ericaceae). Mol Ecol 15:1165-1173.

Hokanson K, J Hancock 2000 Early-acting inbreeding depression in three species of Vaccinium (Ericaceae). Sex Plant Reprod 13:145150.

Inouye DW, GH Pyke 1988 Pollination biology in the Snowy Mountains of Australia: comparisons with montane Colorado, USA. Aust J Ecol 13:191-210.

Kameyama Y, G Kudo 2009 Flowering phenology influences seed production and outcrossing rate in populations of an alpine snowbed shrub, Phyllodoce aleutica: effects of pollinators and self-incompatibility. Ann Bot 103:1385-1394.

Kudo G 1991 Effects of snow-free period on the phenology of alpine plants inhabiting snow patches. Arct Alp Res 23:436-443.

1993 Relationship between flowering time and fruit set of the entomophilous alpine shrub, Rhododendron aureum (Ericaceae), inhabiting snow patches. Am J Bot 80:1300-1304.

Kudo G, S Suzuki 2002 Relationships between flowering phenology and fruit-set of dwarf shrubs in alpine fellfields in northern Japan: a comparison with a subarctic heathland in northern Sweden. Arct Antarct Alp Res 34:185-190.

Lloyd DC, JMA Yates 1982 Intrasexual selection and the segregation of pollen and stigmas in hermaphrodite plants, exemplified by Wablenbergia albomarginata (Campanulaceae). Evolution 36:903-913.

Macior LW 1966 Foraging behavior of Bombus (Hymenoptera: Apidae) in relation to Aquilegia pollination. Am J Bot 53:302-309.

Moeller DA 2006 Geographic structure of pollinator communities, reproductive assurance, and the evolution of self-pollination. Ecology 87:1510-1522.

Naito K, Y Isagi, N Nakagoshi 1998 Isolation and characterization of microsatellites of Rhododendron metternichii Sieb. et Zucc. var. hondoense Nakai. Mol Ecol Notes 7:925-931.

Nuortila C, J Tuomi, J Aspi, K Laine 2006 Early-acting inbreeding depression in a clonal dwarf shrub, Vaccinium myrtillus, in a northern boreal forest. Ann Bot Fennici 43:36-48.

Nuortila C, J Tuomi, K Laine 2002 Inter-parent distance affects reproductive success in two clonal shrubs, Vaccinium myrtillus and Vaccinium vitis-idaea (Ericaceae). Can J Bot 80:875-884.

Olsen KM 1997 Pollination effectiveness and pollinator importance in a population of Heterotheca subaxillaris (Asteraceae). Oecologia 109:114-121.

Ono A, I Dohzono, T Sugawara 2008 Bumblebee pollination and reproductive biology of Rhododendron semibarbatum (Ericaceae). J Plant Res 121:319-327.

Ramsey M 1995a Causes and consequences of seasonal variation in pollen limitation of seed production in Blandfordia grandiflora (Liliaceae). Oikos 73:49-58.

- 1995b Ovule pre-emption and pollen limitation in a selffertile perennial herb (Blandfordia grandiflora, Liliaceae). Oecologia 103:101-108.

Ranta E, H Lundberg 1981 Resource utilization by bumblebee queens, workers and males in a subarctic area. Holarct Ecol 4: 145-154.

Raspé O, P Guillaume, A-L Jacquemart 2004 Inbreeding depression and biased paternity after mixed-pollination in Vaccinium myrtillus L. (Ericaceae). Int J Plant Sci 165:765-771.

Tomono T, T Sota 1997 The life history and pollination ecology of bumblebees in the alpine zone of central Japan. Jpn J Entomol 65: 237-255.

Waser NM, MV Price 1991 Reproductive costs of self-pollination in Ipomopsis aggregata (Polemoniaceae): are ovules usurped? Am J Bot 78:1036-1043.

Weir BS 1996 Genetic data analysis. II. Methods for discrete population genetic data. Sinauer, Sunderland, MA.

Young HJ, DW Dunning, KW von Hasseln 2007 Foraging behavior affects pollen removal and deposition in Impatiens capensis (Balsaminaceae). Am J Bot 94:1267-1271. 